\title{
Title: MUSCLE AND FAT AFTEREFFECTS AND THE ROLE OF GENDER: IMPLICATIONS FOR BODY IMAGE DISTURBANCE
}

\author{
Short title: ROLE OF GENDER IN FAT AND MUSCLE AFTEREFFECTS
}

Kevin R. Brooks ${ }^{1,2,3 *}$, Edwina Keen ${ }^{1}$, Daniel Sturman ${ }^{1}$, Jonathan Mond ${ }^{4,5}$, Richard J. Stevenson ${ }^{1,2,3}$, and lan D. Stephen ${ }^{1,2,3}$

${ }^{1}$ Department of Psychology, Macquarie University

2 Perception in Action Research Centre (PARC), Faculty of Human Sciences, Macquarie University

${ }^{3}$ Body Image and Ingestion Group (BIIG), Macquarie University

${ }^{4}$ Centre for Rural Health, University of Tasmania

${ }^{5}$ Translational Health Research Institute, School of Medicine, Western Sydney University, School of Medicine, Western Sydney University,

${ }^{*}$ Requests for reprints should be addressed to Kevin Brooks, Department of Psychology, Macquarie University, Sydney, NSW 2109, Australia (e-mail: kevin.brooks@mq.edu.au).

The data that support the findings of this study are available from the corresponding author upon request.

\footnotetext{
Abstract:

Body image disturbance - a cause of distress amongst the general population and those diagnosed with various disorders - is often attributed to the media's unrealistic depiction of ideal bodies. These ideals are strongly gendered, leading to pronounced fat concern amongst females, and a male preoccupation with muscularity. Recent research suggests that visual aftereffects may be fundamental to the misperception of body fat and muscle mass - the perceptual component of body image disturbance. This study sought to establish the influence of gender on these body
} 
aftereffects. Male and female observers were randomly assigned to one of four adaptation conditions (low fat, high fat, low muscle, and high muscle bodies) and were asked to adjust the apparent fat and muscle levels of male and female bodies to make them appear as 'normal' as possible both before and after adaptation. While neither the gender of observers or of body stimuli had a direct effect, aftereffect magnitude was significantly larger when observers viewed owngender (compared to other-gender) stimuli. This effect, which may be due to attentional factors, could have implications for the development of body image disturbance, given the preponderance of idealised own-gender bodies in media marketed to male and female consumers.

\section{Keywords:}

Aftereffects, body size \& shape misperception, visual adaptation, body image, gender 
Body Image Disturbance and the Role of Gender in Fat and Muscle Aftereffects

Body image disturbance is generally acknowledged to include two fundamental components (Garner \& Garfinkel, 1981; Cash \& Deagle, 1997). While the perceptual aspect referred to as body size and shape misperception (BSSM) - involves the judgement that one's body is larger or smaller than it truly is (Challinor et al., 2017), the attitudinal aspect - often referred to as body dissatisfaction - is concerned with an individual's feelings about their size and shape (Cash \& Brown, 1987). These two components often co-occur (e.g. Caspi et al., 2016; Taylor \& Cooper, 1992), and have related associations and consequences. BSSM is a risk factor for depression and the development of eating disorders (Caspi et al., 2016; Cornelissen, McCarty, Cornelissen, \& Tovée, 2017; Gardner \& Brown, 2014; Molbert et al., 2017). Similarly, body dissatisfaction both among males (Griffiths, Mitchison, Mond et al., 2016) and females (Mond, Mitchison et al., 2013) is associated with many adverse consequences, including depression and low self-esteem (Paxton et al., 2006), and the development of conditions such as anorexia nervosa (Stice \& Shaw, 2002) and muscle dysmorphia (Specter \& Wiss, 2014). While the causes of body image disturbance and related disorders are complex and varied, the media is frequently ascribed a critical role. Specifically, internalization of media portrayals of extremely thin females and muscular males is thought to underpin erroneous perception of the self (Lopez-Guimera, Levine, Sanchez-Carracdeo, \& Fauquet, 2010). While media influences have frequently been explored through social comparison frameworks (e.g. Harrison, 2000; Hobza et al., 2007; Lin \& Kulik, 2002), recent research has attempted to uncover the perceptual mechanism behind the misperception of body size and shape. It has been suggested that this mechanism is the wellknown phenomenon of adaptation (Challinor et al., 2017; Brooks et al., in press).

\section{The Adaptation Model of Body Size and Shape Misperception}

Visual adaptation is a phenomenon in which extended exposure to a stimulus causes an "aftereffect" in the form of a perceptual bias, distorting the appearance of subsequently seen stimuli (Thompson \& Burr, 2009). A well-known example is the motion aftereffect (Addams, 1884; 
Mather, Verstraten \& Anstis, 1998). After viewing an "adaptation stimulus" featuring downward motion for a short duration (e.g. 30seconds), stationary objects appear to move upwards - the opposite direction to the adapting stimulus. Similar effects have been documented for other visual properties such as colour, orientation, or even complex attributes such as the gender of faces. For example, prolonged viewing of a typically female face can cause androgynous faces to appear distinctly masculine, and vice versa (Webster, Kaping Mizokami, \& Duhamel, 2004). More recently, Winkler and Rhodes (2005) revealed that after exposure to horizontally compressed photos of human bodies, the body selected as most normal looking was thinner, compared to the pre-adapted selection, and vice versa. While these rudimentary image manipulations are somewhat unrealistic, the results have been corroborated by independent replications using the same technique (Brooks et al., 2018), and experiments using computer generated images simulating various Body Mass Index (BMI) values (Glauert et al., 2009; Sekunova, Black, Parkinson \& Barton, 2013), or photographs altered using more realistic transformations (Brooks et al., 2016; Hummel et al. 2012a,b; Stephen et al., 2016). These examples may have relevance to real-world cases of BSSM. If those who consume media featuring unusually thin models were to inspect their own body (in a mirror, for example), a visual aftereffect in this context would lead to the conclusion that they are considerably larger than they really are.

Despite the use of various techniques, the aforementioned body adaptation studies all used manipulations mimicking changes of body fat. While body fat is a significant contributor to body size, and one that often forms the focus of eating disorder sufferers' body image concerns, it is by no means the only important component of body composition. Muscularity is another critical dimension, and a source of BSSM for some, including those diagnosed with muscle dysmorphia. As with the overestimation of body fat, the underestimation of muscle mass has been attributed to the promotion of a muscular ideal by the media (Leit, Gray, \& Pope Jr, 2002; Pope Jr, Olivardia, Gruber, \& Borowiecki, 1999). If adaptation plays a role in these cases, it should be possible to demonstrate a misperception of muscularity as a consequence of laboratory exposure to images of muscular individuals. Recent research has presented evidence of such an effect, and has 
demonstrated that aftereffects of muscle and fat are independent (Sturman, Stephen, Mond, Stevenson, \& Brooks, 2017).

\section{Gendered Body Fat and Muscle Mass Ideals}

In regard to the figure-based concerns of the general population, a clear gender difference emerges when considering body composition as a two-dimensional construct. For females, body fat plays a role of particular salience, while muscle mass is a more prominent issue for males (McCreary \& Sasse, 2000). For example, while females, on average, consider the ideal figure to be thinner than their perceived current form, males do not rate their own thinness as significantly different from the ideal. However, while males desire a significantly more muscular body, females do not, rating themselves as marginally more muscular than the ideal figure (Grossbard, Neighbors, \& Larimer, 2011). Similarly, Vartanian et al. (2001) showed that while similar proportions of males considered themselves to be either too fat $(27 \%)$ or too thin $(26 \%)$, the discrepancy was large for females (56\% vs $3 \%$ respectively). Yet for the muscularity dimension, it is males who show a large discrepancy $(85 \%$ wishing to be more muscular, with only $2 \%$ wishing to reduce their muscularity). In this study, females also showed a slight overall preference for increased muscularity, although this was markedly less pronounced (rates of $56 \%$ and $22 \%$ respectively). Further, while the drive for muscularity is associated with higher levels of depression and lower levels of self-esteem in young males, there is no such association for females (McCreary \& Sasse, 2000). In addition, males' underestimation of muscularity, but not their exaggeration of fat, is correlated positively with depression and negatively with self-esteem, reaffirming that muscularity holds more importance for males (Olivardia et al., 2004). Differences of this kind observed in the general population are reflected in the gendering of clinical manifestations of body image disturbance, i.e., anorexia nervosa predominating in females and muscle dysmorphia in males (Mitchison \& Mond, 2015; Murray, Griffiths, \& Mond, 2016; Murray et al., 2017).

\section{The Present Study}


Although fat/muscle-based gender differences in the attitudinal aspects of body image are well-known, there is currently no information available on gender differences in perceptual distortions for these dimensions of body composition. Given the links between attitudinal and perceptual aspects of body image disturbance, it may be reasonable to expect similar patterns of results. Further, no studies have examined gender differences in terms of the magnitude of body size and shape aftereffects. If the BSSM issues experienced in the real-world are underpinned by adaptation to idealised images of bodies in the media, it is plausible that the observed gender differences may have an adaptation-based explanation. For example, an increased susceptibility of female observers to visual aftereffects of fat, and of male observers to aftereffects of muscle, possibly mediated by differences in attention to these dimensions of body composition, could contribute to gender differences. Alternatively, observations of increased malleability of the mental representation of fat mass for female bodies, and of muscle mass for male bodies, may provide an explanation for real-world gender differences in fat and muscle misperception.

This study aimed to investigate the influence of gender upon misperceptions of fat and muscle induced by visual adaptation. By exposing both male and female observers to adapting images of male or female body stimuli that are high or low in body fat or muscle mass, we seek to compare the size of these effects between male and female observers and stimuli for the first time.

Firstly, it is expected that, in line with Sturman et al. (2017), contrasting aftereffects will be demonstrated following exposure to large and small bodies. While exposure to high levels of fat or muscle should result in elevated points of subjective normality (PSNs), exposure to low levels should reduce the PSN. Furthermore, separate aftereffects should be observed following exposure to bodies that are extreme in terms of their simulated fat vs. muscle mass. Our second group of predictions concerns the effects of participant gender. It is proposed that aftereffects of fat will be larger for female than for male observers, and that aftereffects of muscle will be larger for male than for female observers. The third group of predictions concerns the effects of stimulus gender, proposing that aftereffects of fat will be larger for female than for male stimuli, and that aftereffects of muscle will be larger for male than for female stimuli. 


\section{Method}

Methodological details were identical to those described in Sturman et al. (2017), except for the number of observers, and the ratio of participants of each gender. This study was performed in accordance with the relevant guidelines and regulations, and was approved by the University's Human Research Ethics Committee.

\section{Observers}

128 undergraduate student observers were recruited (64 males, 64 females), either through the University's Psychology Participant Pool (receiving course credit), or through e-mails to friends (receiving $\$ 20$ compensation for their time). All had normal or corrected to normal vision, were over 18 years of age $(M=21.75$ years, $S D=4.25)$ and were naïve to the experimental hypotheses. While the results of 64 of these participants (39 females, 25 males), have already been reported Sturman et al. (2017), the aforementioned report did not investigate the issue of gender, either of the observers or the stimuli. To allow analysis based on gender we recruited an additional 64 participants ( 25 females, 39 males) to form appropriately balanced groups, and to match the power of the previous investigation for analyses involving observer gender. Results for one participant were discarded due to an administrative error, and an additional participant was recruited to balance the experimental groups. All observers gave informed consent before participating.

\section{Stimuli and Apparatus}

Stimuli were sourced from a database of images used in previous studies (Brierley, Brooks, Mond, Stevenson, \& Stephen, 2016; Sturman, Stephen, Mond, Stevenson, \& Brooks, 2017). Photographs were taken of subjects wearing standardised tight fitting grey singlets and shorts, posed in a standardised anatomical position from a frontal view. These were taken inside a booth painted in Munsell N5 neutral grey, and illuminated with 15 high accuracy d65 fluorescent Philips tubes in high frequency fixtures to reduce the effects of flicker. A Canon 50D digital camera was used, with exposure, ISO and custom white balance held constant. A Tanita SC 330 body 
composition analyser measured weight, body fat and muscle mass, while a fixed measuring tape was used to measure height.

Images of male and female subjects were treated separately. The background of all images was rendered a uniform grey. Stimuli were then manipulated independently in terms of their apparent body fat and muscle mass using Psychomorph version 6 (Tiddeman, Burt \& Perrett, 2001). For each image, 130 landmark points were marked to delineate the features of the body. Regression analyses were used to calculate a standardised body fat score for each body that controlled for muscle mass and height, and a standardised muscle mass score that controlled for body fat and height (Brierley et al., 2016). Images with muscle mass more than 1 standard deviation from the mean were temporarily removed, after which the images were ranked by standardised body fat scores. The 10 highest ranked images for each sex were grouped, and the location of each landmark point was averaged to create a 'high fat' prototype for each sex, while the lowest 10 were averaged to create a 'low fat' prototype. The same process was repeated using muscle mass scores to create the 'high muscle' and 'low muscle' prototypes for each sex. However, due to the smaller sample of males with extreme muscle and average fat, only 5 images were used for the male 'muscle' prototypes. The difference in mean body fat and muscle mass for each prototype can be seen in Table 1. Independent samples t-tests showed significant differences in fat levels, but not muscle levels, for the 'fat' prototypes, and significant differences in muscle levels, but not fat levels, for the 'muscle' prototypes.

These prototype images allowed us to define the image transformations that accompany increases or decreases in body fat or muscle independently of any other aspects of the image, using Psychomorph. Twenty-five male and 25 female images with both body fat and muscle mass scores less than 1 standard deviation from the mean that were not used in the creation of the prototypes were selected as test identities for fat and muscle transformations.

Each image was manipulated in 13 equidistant steps along the body fat dimension from a manipulation of $100 \%$ of the difference between the prototypes towards the low fat prototype and ending with a $100 \%$ manipulation towards the high fat prototype. Each of the 13 images were then 
individually manipulated in 13 equidistant steps along the muscle mass dimension from $100 \%$ of the difference between the prototypes towards the low muscle prototype and ending with a $100 \%$ manipulation towards the high muscle prototype. This resulted in a two-dimensional grid of images that increased incrementally by 13 steps along the body fat dimension and 13 steps along the muscle mass dimension, resulting in a set of 169 images for each test identity (see end-points for one male and one female subject in Figure 1).

Images were formatted to $600 \times 900$ pixels for use as test stimuli and $450 \times 675$ pixels for use as adaptation stimuli to avoid low-level retinotopic adaptation aftereffects. The face of each image was obscured with a black square. For each observer, five identities were randomly selected as practice identities, 10 identities were randomly selected as test stimuli and the remaining 10 identities were used as the adaptation stimuli.

A body manipulation tool divided the monitor into an invisible grid of 169 cells (13 cells across and 13 cells high), which correspond to the 169 images for each identity. When the mouse cursor, which was not visible to the observers, was placed over a cell the image with the corresponding fat and muscle score was displayed on the monitor. This allowed for independent manipulation of the dimensions of body fat and muscle mass using horizontal and vertical mouse movements. The initial fat and muscle value of the stimulus was randomised, and the location of the mouse cursor was not visible.

Matlab ® version 8.3 (R2014a) using Psychophysics Toolbox Version 3 (Kleiner et al., 2007) was used to present all stimuli (including the body manipulation tool) and to control the experimental procedure. Images were displayed on a 19" Samsung 943BW colour monitor with a resolution of $1600 \times 900$ pixels.

\section{Procedure}

Male and female observers were randomly allocated to one of four adaptation conditions; low muscle, high muscle, low fat, or high fat. The experiment consisted of three phases; a practice block, a baseline block, and an adaptation block. All observers completed the procedure twice once with male stimuli and once with female stimuli - in a counterbalanced order. Within each 
session there were 3 phases - practice, baseline testing and adaptation testing - all of which involved stimuli of the same gender. To minimise carry over effects, a ten-minute break was given between the first and second session. The duration of the entire experiment was approximately 30 minutes.

In the practice phase, observers were given instructions to manipulate each body stimulus using mouse movements until it appeared 'as normal as possible'. However, they were not informed that they were manipulating fat and muscle, or which dimension or direction of mouse movement corresponded to which dimension or direction of body composition change. When satisfied with their manipulation, observers clicked the mouse to end the trial and proceeded to the next stimulus. The sound of a bell indicated the start of a new trial. Five practice identities were randomly selected from the 25 available stimuli of a given gender. No data were recorded during the practice phase.

For baseline testing, observers were given identical instructions to those given in the practice phase. Ten randomly selected identities not used in the practice block were each presented twice in a pseudo-random order, such that all identities were presented once before repetition. No identity was presented twice in a row. At the conclusion of each trial, the body fat and muscle mass of the chosen image was recorded. Baseline PSNf (point of subjective normality: fat) and $\mathrm{PSN}_{\mathrm{m}}$ (point of subjective normality: muscle) were calculated as the average body fat and muscle mass settings respectively across all 10 baseline test identities, and across both repetitions.

The adaptation test block was identical to the baseline test block, except in the following respects. The 10 remaining test identities (not used for practice or baseline tests) were designated as adaptation stimuli. "Initial" adaptation involved exposure to these stimuli for a total of $120 \mathrm{~s}$ initial adaptation time (2 s per presentation, repeated 6 times for each of the 10 identities, shown in a random order), before the manipulation of any test stimulus. To prevent the decay of aftereffects during the experimental session, top-up adaptation was presented in between each test stimulus. This consisted of 6 identities (randomly selected from the 10 adaptation stimuli on 
each top-up), each presented for $1 \mathrm{~s}$ resulting in a total of $6 \mathrm{~s}$ for each top-up adaptation. The level of fat and muscle displayed in the adaptation stimuli were based on the observer's baseline PSN and $\mathrm{PSN}$ settings. Those in the high and low fat conditions were presented with adaptation images that were 6 image steps higher (to a maximum of the largest stimulus available) or lower (to a minimum of the smallest stimulus available) than their baseline PSN $\mathrm{f}_{\mathrm{f}}$ and those in the high and low muscle conditions were given adaptation images 6 steps higher or lower than their baseline $\mathrm{PSN}_{\mathrm{m}}{ }^{1}$.

After testing, the two dependent variables - change in point of subjective normality for body fat $\left(\triangle P S N_{f}\right)$ and change in point of subjective normality for muscle mass $\left(\triangle P S N_{m}\right)-$ were calculated separately by subtracting the PSN from the baseline block from the PSN recorded in the adaptation block. These values are expressed in terms of the percentage of the extremity of the adapting stimulus. While a positive $\triangle \mathrm{PSN}$ represents an increase in the fat or muscle levels that are considered to be normal (and hence a visual aftereffect of size reduction), a negative $\triangle P S N$ represents a reduction (and hence a visual aftereffect of size increase) as a result of adaptation.

\section{Results}

The first set of predictions concerned confirmation of previous fat and muscle aftereffect demonstrations. Relevant data are shown in in figure 2, where changes in points of subjective normality for fat and muscle (the two dependent variables $\Delta P S N_{f}$ and $\Delta P S N_{m}$, respectively) are plotted simultaneously in a 2-D Cartesian "Body Space”. From informal observation, it appears that exposure causes the PSN to be shifted towards the adaptation stimulus, along the relevant

\footnotetext{
${ }^{1}$ As expected, the adaptation levels used were frequently fewer than six stimulus steps above or below the baseline level (i.e. on $42 \%$ of occasions - see Table 3, Appendix). To check for systematic bias in the adaptation levels used for own- vs other-gender adaptation conditions, we performed two $2 \times 2$ ANOVAs (one for fat, and one for muscle adaptation conditions). While a main effect of adaptation direction confirmed that adaptation levels were significantly different for high vs. low fat $(\mathrm{F}(1,60)=$ 1836.602, $\left.\mathrm{p}<0.0005, \eta_{\mathrm{p}}{ }^{2}=.967\right)$ and for high and low muscle conditions $\left(\mathrm{F}(1,60)=2013.309, \mathrm{p}<0.0005, \eta_{\mathrm{p}}{ }^{2}=.970\right)$ as expected, there were no significant effects involving gender congruence. Further, we analysed the extremity of the adaptor, in terms of its difference (in stimulus steps) from each participant's baseline PSN (see Table 4, Appendix). Again, main effects confirmed a significant difference between for high and low fat conditions $\left(F(1,60)=2569.403, p<0.0005, \eta_{\mathrm{p}}{ }^{2}=.976\right)$ and for high and low muscle conditions $\left(\mathrm{F}(1,60)=2727.391, \mathrm{p}<0.0005, \eta_{\mathrm{p}}{ }^{2}=.978\right)$, effects involving gender congruence were not significant.
} 
axis. Hence, high (low) fat adaptation causes an increase (decrease) in PSN $\mathrm{P}_{\text {, }}$ while high (low) muscle adaptation causes an increase (decrease) in $\mathrm{PSN}_{\mathrm{m}}$. In general, ratings for the body space dimension that was not adapted appear to be affected only minimally. These informal observations were confirmed in two $2 \times 2$ between subjects ANOVAs ${ }^{2}$, each concerning one of the two dependent variables $\left(\triangle P S N_{f}\right.$ and $\left.\triangle P S N_{m}\right)$. When analysing changes of perceived body fat, as expected there was a main effect of adaptation direction on $\Delta \mathrm{PSN}_{\mathrm{f}}$, showing that adaptation to images high in fat or muscle produced more positive shifts than low fat or muscle adaptors, $\mathrm{F}(1,124)=96.458, p<.0005, \eta^{2}=.438$. A significant interaction between adaptation direction $\mathrm{x}$ adaptation dimension, $\mathrm{F}(1,124)=53.890, p<.0005, \eta_{\mathrm{p}}^{2}=.303$ confirmed that $\Delta \mathrm{PSN}$ settings were affected differently by fat and muscle adaptation, with larger effects for fat adaptation. Considering changes in perceived muscle mass, a complimentary pattern of results emerges. Again, a main effect of adaptation direction on $\triangle \mathrm{PSN}$ demonstrates that high fat or muscle adaptors produced more positive shifts than low fat or muscle adaptors, $\mathrm{F}(1,124)=43.697, p<$ $.0005, \eta_{p}^{2}=.261$. A significant interaction between adaptation direction $\mathrm{x}$ adaptation dimension, $\mathrm{F}(1,124)=4.081, p=.046,=.032$ confirmed that muscle adaptation has a significantly greater effect on $\triangle P S N_{m}$ than fat adaptation. These results confirm the effectiveness of images high and low in fat and muscle in producing visual adaptation, and the independence of the fat and muscle aftereffects.

The second set of predictions concerned differences in adaptation patterns between observers of different genders (see figure 3), while the third concerned differences when using stimuli of different genders (figure 4). To test these predictions, a pair of 2 (adaptation direction) $\mathrm{x}$ 2 (observer gender) $\times 2$ (stimulus gender) mixed ANOVAs was conducted. The first, including only conditions where adaptors were high or low in fat, used $\triangle \mathrm{PSN}$ as the dependent variable. Although a main effect of adaptation direction was again demonstrated $F(1,60)=106.627, p<$

\footnotetext{
${ }^{2}$ Inspection of Q-Q plots and statistical tests failed to find evidence of substantial departures from normal distribution (3 significant results out of 32 conditions in Kolmogorov-Smirnoff and Shapiro-Wilk tests). Levene's test gave no reason to reject the null hypothesis that the error variance of any dependent variable was equal across groups (homoscedasticity assumption). As such, ANOVA, which is robust to violations of the assumption of normality (Blanca, Alarcón, Bono \& Bendayan, 2017), and is robust to violations of homoscedasticity when sample sizes are equal, was considered an appropriate test.
} 
$.0005, \mathrm{np}^{2}=.640$, neither the interaction between adaptation direction and observer gender nor the interaction between adaptation direction and stimulus gender was significant $(p>.05)$. However, a significant 3-way interaction between adaptation direction, observer gender and stimulus gender was demonstrated $F(1,60)=5.119, p=.8027, \eta_{p}^{2}=.079$. The second $2 \times 2 \times 2$ ANOVA was restricted to conditions where adaptors were high or low in muscle, and used $\triangle P S N_{m}$ as the dependent variable. As in the fat analysis, a main effect of adaptation direction $\mathrm{F}(1,60)=31.638, p$ $<.0005, \eta_{p}^{2}=.345$, was accompanied by neither an interaction between adaptation direction and observer gender, nor an interaction between adaptation direction and stimulus gender $(p>.05)$. Again, a significant 3-way interaction was evident $\mathrm{F}(1,60)=6.106, p=.016, \mathrm{np}^{2}=.092$.

To further investigate the unanticipated 3-way interaction for both dependent variables, additional analyses were conducted. Independent variables concerning observer gender (male/female) and stimulus gender (male/female) were replaced with a new variable named "gender match" (same/different), concerning the congruence of gender between observer and stimulus. Results pertaining to this analysis can be seen in figure 5 . Concerning the $\triangle P S N_{f}$ dependent variable, a 2 (adaptation direction) $\times 2$ (gender congruence) ANOVA using only the fat adaptation conditions, again showed a main effect of adaptation direction $\mathrm{F}(1,62)=105.499, p<$ $.0005, \mathrm{n}^{2}=.630$, accompanied by a significant adaptation direction $\mathrm{x}$ gender congruence interaction $F(1,62)=4.928, p=.030, \eta_{p}^{2}=.074$. Similarly, when analysing the $\Delta P S N_{m}$ dependent variable, a 2 (adaptation direction) x 2 (gender congruence) ANOVA using only the muscle adaptation conditions showed a main effect of adaptation direction $\mathrm{F}(1,62)=32.624, p<.0005$, $\eta_{\mathrm{p}}^{2}=.345$, with a significant adaptation direction $\mathrm{x}$ gender congruence interaction $\mathrm{F}(1,62)=5.989$, $p=.017, \eta_{p}^{2}=.088$. These results demonstrate that for both adaptation to extreme levels of fat and adaptation to extreme levels of muscle, aftereffects are significantly larger when observers view stimuli of their own gender, compared to other gender stimuli ${ }^{3}$.

\footnotetext{
${ }^{3}$ At the request of an anonymous reviewer, additional unplanned statistical tests were performed to check whether there were significant differences in the baseline PSNs for muscle or fat for own- vs. other-gender stimuli (see Table 2, Appendix, for means and SDs). In these two 2x2 ANOVAs (one for perceived fat, one for perceived muscle), no statistically significant effects emerged (all p's > 0.05).
} 


\section{Discussion}

\section{Aftereffects of Fat and Muscle}

Results of the present investigation corroborate the findings of Sturman et al. (2017) in demonstrating a dissociation between visual processing and encoding of body fat and muscle mass. If the visual system confounded fat and muscle, instead encoding only the property of body size, exposure to bodies that are low (high) in terms of fat and muscle should have produced the same effects. This was not the case. When adaptation stimuli are low (high) in terms of their levels of body fat, significant body fat aftereffects are produced such that subsequently viewed stimuli appear higher (lower) in fat, and the perception of normality is shifted in the direction of adaptation. This is consistent with adaptation producing an aftereffect of increased (decreased) body fat, such that the participant must decrease (increase) fat levels to produce an image that appears normal. However, these adaptation stimuli cause little or no change in perceived levels of muscle mass. In contrast, for adaptation stimuli that are low (high) in muscle mass, significant aftereffects of perceived muscularity are produced, aligning with the direction of adaptation. Body fat aftereffects produced using these adaptation stimuli are minimal. While the use of previously reported data from Sturman et al. (2017) means that these findings do not represent an independent replication, they nevertheless demonstrate that the additional participants used in this study behave in a consistent way. The results continue to suggest that the two dimensions of body composition - fat and muscle - are processed by neural populations that are largely dissociated. Rather than simply involving the encoding of body size alone, the perceptual encoding of body stimuli involves separate fat and muscle norms that are continually updated with reference to recently encountered stimuli (Sturman et al., 2017). As previously suggested, these results may have important implications for exposure to the unrealistic body standards depicted in the media and the development of disordered perceptions of one's own body.

While these measurements are consistent with the idea of a shift in the appearance of test stimuli following exposure, it should be remembered that, as for all other perceptual aftereffects, 
they may also be consistent with changes in decision criteria. This possibility is often overlooked for low-level adaptation (e.g. the motion aftereffect mentioned in the introduction), partially due to the compelling nature of the aftereffects, and to the fact that more rigorous measurement techniques are available (Storrs, 2015). Adaptation to high-level stimulus attributes such as body size and shape often produces more subtle effects that may be interpreted as changes in the criterion for what constitutes "normality" (or averageness), with no actual change in perception per se. While this observation may be important when attempting to uncover the underlying mechanisms of high-level perception, in terms of the application to real-world instances of body image disturbance, the issue of whether the effect is strictly perceptual or involves a decision-level bias may be moot. Either way, these phenomena are apparent in the real-world, both in terms of body fat and muscle mass, and are associated with significant distress for those affected.

\section{Effects of Observer Gender and Stimulus Gender}

The present investigation extended upon currently available literature by investigating the role of gender in body fat and muscle mass aftereffects. The gender-based a priori predictions of the current investigation were not supported. Conditions involving female observers or stimuli did not involve larger fat aftereffects than those involving male observers/stimuli, and conditions with male observers/stimuli did not involve larger muscle aftereffects than those involving female observers/stimuli. As such, it does not appear that gender differences in the rates of occurrence of muscle and fat concerns can be explained by gender differences in susceptibility to fat and muscle aftereffects, or by gender differences in the malleability of mental representations of body fat or muscularity, in response to adaptation. Nevertheless, adaptation-based explanations cannot be ruled out. To allow a fair comparison between the effects of adaptation to bodies that were high and low in fat or muscle, the current study employed adaptation stimuli of female and male bodies with matched levels of muscle and fat mass, presented to observers of each gender for equal periods of time. However, in the real-world, media targeted at male consumers features rather different male and female body compositions to those promoted in media marketed to females (e.g., Frederick, Fessler, \& Haselton, 2005), leading to very different patterns of exposure. While 
males tend to be more frequently exposed to highly muscular male bodies in the media they choose to consume (e.g., professional sportsmen), females tend to be more frequently exposed to very thin female bodies (e.g., fashion models). These patterns alone allow us to predict adaptation-induced gender differences in the fat and muscle levels that constitute the norm for females and males without the need to appeal to differences in susceptibility, or to differences in the malleability of the representation of fat and muscle mass.

\section{Effect of Gender Congruence}

While the predicted straightforward effects of observer gender and stimulus gender failed to materialise, an unexpected, more complex effect of gender was evident. For both the muscle and fat dimensions, aftereffects were larger when observers were exposed to and judged bodies from their own gender group, compared to bodies of a different gender. This effect is reminiscent of the previous demonstration that aftereffects of perceived gender typicality can be enhanced when participants are exposed to body silhouettes of their own gender (Palumbo et al., 2013). Although the reasons for this effect are not clear, attention may be considered a potential contributor.

It has been shown, across a variety of paradigms, that where females tend to pay more attention to other females, males tend to preferentially attend to other males. As children progress developmentally, they tend to exhibit a significantly greater preference for watching own-gender models rather than other-gender models (Slaby \& Frey, 1975). In studies measuring adult subjects' eye movements, similar patterns of fixations arise (Hewig et al., 2008; Mercer Moss, Baddeley, Canagarajah, 2012). Previous studies have demonstrated that when attention is directed toward a target stimulus, neural activity is amplified (e.g. Pestilli, Viera, \& Carrasco, 2007). The increased neural activity is associated with more substantial adaptation, eliciting greater aftereffects for stimuli that are the subject of attention. One example of the attentional enhancement of adaptation is the case of attention contingent motion aftereffects. Here, attending to motion in one direction and ignoring motion in the other direction produces an aftereffect congruent with direction to which attention was directed (Culham, Verstraten, Ashida, \& Cavanagh, 2000). Similar results have been reported for high-level aspects of complex stimuli 
such as facial identity (Rhodes et al., 2011). More recently, attentional effects have been shown in two empirical demonstrations of body size and shape aftereffects (Stephen et al., 2018; 2019). Although the source of the own-gender bias demonstrated in this study cannot be confirmed, it seems likely that this could be explained by enhanced attention to own gender stimuli, resulting in larger aftereffects for these conditions.

Regardless of its root cause, the observation of larger aftereffects for own gender stimuli may have relevance for real-world examples of BSSM. The suggestion that adaptation may underlie such cases is predicated on the idea that exposure to idealised bodies may cause a change to the observer's perception of body size and shape, which is manifested when the observer views their own body (for example, in a mirror). Given the prevalence of idealised owngender models that appear in media marketed to males and females, and the body composition of these figures (Frederick et al., 2005), this means that adaptation is more likely to occur, and may be larger in magnitude in the real-world than if adaptation had been larger for other-gender stimuli. Consistent with this result and its implications, it has recently been demonstrated that aftereffects are larger when the gender of adaptation and test stimuli are congruent, as they were in this study (Brooks et al., 2019).

\section{Conclusions}

Visual adaptation to bodies that are extreme in their level of fat or muscle can cause aftereffects of perceived body size and shape. While adaptation to low (high) levels of fat causes subsequently seen bodies to appear higher in fat than they really are, adaptation to low (high) levels of muscle causes similar perceptual distortions of increased (decreased) muscularity. These effects do not differ significantly between male vs. female observers, or between male vs. female body stimuli. However, both males and females exhibit significantly larger aftereffects following exposure to own gender compared to other gender stimuli. These findings suggest distinct differences in the way in which gendered body stimuli are encoded. While the mechanisms by which these trends arise are presently unclear, an attentional bias is proposed. 


\section{References}

Addams, R. (1834). An account of a peculiar optical phænomenon seen after having looked at a moving body. London \& Edinburgh Philosophical Magazine and Journal of Science, 5(29), 373-374. doi:10.1080/14786443408648481

American Psychiatric Association. (2013). Diagnostic and Statistical Manual of Mental Disorders: DSM-5 (5th ed.). Arlington, VA: American Psychiatric Publishing Inc.

Benton, C., \& Karazsia, B. T. (2015). The effect of thin and muscular images on women's body satisfaction. Body Image, 13, $22-27$.

Brierley, M. E., Brooks, K. R., Mond, J., Stevenson, R. J., \& Stephen, I. D. (2016). The Body and the Beautiful: Health, Attractiveness and Body Composition in Men's and Women's Bodies. PLoS One, 11(6), e0156722. doi:10.1371/journal.pone.0156722

Brooks, K. R., Baldry, E., Mond, J., Stevenson, R. J., Mitchison, D., \& Stephen, I. D. (2019). Gender and the Body Size and Shape Aftereffect: Implications for neural processing. PsyArXiv,

Brooks, K. R., Mond, J., Mitchison, D., Stevenson, R. J., Challinor, K. L. \& Stephen, I. D. (in press). Looking at the Figures: Visual Adaptation as a Mechanism for Body Size \& Shape Misperception. Perspectives on Psychological Science.

Brooks, K. R., Mond, J., Stevenson, R., \& Stephen, I. (2016). Body image disturbance and exposure to extreme body types: Contingent adaptation and cross adaptation for self and other. Frontiers in Neuroscience, 10, 334. doi: 10.3389/fnins.2016.00334

Brooks, K. R., Clifford, C. W. G., Stevenson R. J., Mond, J., Stephen, I. D. (2018). The High-level Basis of Body Adaptation. Royal Society Open Science. 5: 172103.

\section{http://dx.doi.org/10.1098/rsos.172103}

Cash, T. F., \& Deagle III, E. A. (1997). The nature and extent of body-image disturbances in anorexia nervosa and bulimia nervosa: A meta-analysis. International Journal of Eating Disorders, 22(2), 107-126. 
Cash, T. F., \& Brown, T. A. (1987). Body image in anorexia nervosa and bulimia nervosa: A review of the literature. Behavior modification, 11(4), 487-521.

Caspi, A., Amiaz, R., Davidson, N., Czerniak, E., Gur, E., Kiryati, N., . . Stein, D. (2017). Computerized assessment of body image in anorexia nervosa and bulimia nervosa: comparison with standardized body image assessment tool. Archives of Women's Mental Health, 20(1), 139-147.

Challinor, K. L., Mond, J., Stephen, I. D., Mitchison, D., Stevenson, R. J., Hay, P., \& Brooks, K. R. (2017). Body size and shape misperception and visual adaptation: An overview of an emerging research paradigm. Journal of International Medical Research, 45(6). doi:10.1177/0300060517726440

Cho, A., \& Lee, J. Body dissatisfaction levels and gender differences in attentional biases towards idealised bodies. Body Image, 10, 95-103. doi: 10.1016/j.bodyim.2012.09.005

Cornelissen, K. K., McCarty, K., Cornelissen, P. L., \& Tovée, M. J. (2017). Body size estimation in women with anorexia nervosa and healthy controls using 3D avatars. Scientific Reports, 7(1), 1-15. doi:10.1038/s41598-017-15339-z

Culham, J., Verstraten, F., Ashida, H., \& Cavanagh, P. (2000). Independent aftereffects of attention and motion. Neuron, 28, 607-615. doi: 10.1016/S0896-6273(00)00137-9

Frederick, D. A., Fessler, D. M. T., \& Haselton, M. G. (2005). Do representations of male muscularity differ in men's and women's magazines? Body Image, 2, 81-86.

Gardner, R. M., \& Brown, D. L. (2014). Body size estimation in anorexia nervosa: a brief review of findings from 2003 through 2013. Psychiatry Research, 219(3), 407-410. doi:10.1016/j.psychres.2014.06.029

Garner, D. M., \& Garfinkel, P. E. (1982). Body image in anorexia nervosa: Measurement, theory and clinical implications. The International Journal of Psychiatry in Medicine, 11(3), 263284.

Garner, D. M., Garfinkel, P. E., Schwartz, D., \& Thompson, M. (1980). Cultural expectations of thinness in women. Psychological Reports, 47(2), 483-491. 
Glauert, R., Rhodes, G., Byrne, S., Fink, B., \& Grammer, K. (2009). Body dissatisfaction and the effects of perceptual exposure on body norms and ideals. International Journal of Eating Disorders, 42, 443-452. doi: 10.1002/eat.20640

Griffiths, S., Hay, P., Mitchison, D., Mond, J. M., Mclean, S. A., Rogers, B., . . Paxton, S. J. (2016). Sex differences in the relationships between body dissatisfaction, quality of life and psychological distress. Australian and New Zealand Journal of Public Health, 40(6), 518522. doi:10.1111/1753-6405.12538

Grogan, S. (2016). Body Image: Understanding Body Dissatisfaction in Men, Women and Children. London, UK: Routledge.

Grossbard, J. R., Neighbors, C., \& Larimer, M. E. (2011). Perceived norms for thinness and muscularity among college students: What do men and women really want? Eating Behaviors, 12, 192-199. doi:10.1016/j.eatbeh.2011.04.005

Harrison, K. (2000). The body electric: Thin-ideal media and eating disorders in adolescents. Internal Communication Association, 50, 119- 143. doi: 10.1111/j.14602466.2000.tb02856.x

Hewig, J., Trippe, R. H., Hecht, H., Straube, T., \& Miltner, W. H. (2008). Gender differences for specific body regions when looking at men and women. Journal of Nonverbal Behavior, 32(2), 67-78.

Hobza, C. L., Walker, K. E., Yakushko, O., \& Peugh, J. L. (2007). What about men? Social comparison and the effects of media images on body and self-esteem. Psychology of Men \& Masculinity, 8(3), 161-172.

Holland, G., \& Tiggemann, M. (2016). "Strong beats skinny every time": Disordered eating and compulsive exercise in women who post fitspiration on Instagram. International Journal of Eating Disorders. doi:10.1002/eat.22559

Hummel, D., Rudolf, A. K., Untch, K. H., Grabhorn, R., \& Mohr, H. M. (2012). Visual adaptation to thin and fat bodies transfers across identity. PLoS One, 7(8), e43195.

doi:10.1371/journal.pone.0043195 
Hummel, D., Grabhorn, R., \& Mohr, H. M. (2012). Body-shape adaptation cannot be explained by adaptation to narrow and wide rectangles. Perception, 41(11), 1315-1322. doi:10.1068/p7197

Kleiner, M., Brainard, D., Pelli, D., Ingling, A., Murray, R., \& Broussard, C. (2007). What's new in Psychtoolbox-3. Perception, 36, 1.

Leit, R. A., Gray, J. J., \& Pope Jr, H. G. (2002). The media's representation of the ideal male body: A cause for muscle dysmorphia? International Journal of Eating Disorders, 31(3), 334-338.

Leit, R. A., Pope Jr, H. G., \& Gray, J. J. (2001). Cultural expectations of muscularity in men: The evolution of Playgirl centerfolds. International Journal of Eating Disorders, 29(1), 90-93.

Lin, L. F., \& Kulik, J. A. (202). Social Comparison and Women's Body Satisfaction. Basic and Applied Social Psychology, 24(2), 115-123.

Lopez-Guimera, G., Levine, M., Sanchez-Carracedo, D., \& Fauquet, J. (2010). Influence of mass media on body image and eating disordered attitudes and behaviours in females: A review of effects and processes. Media Psychology, 13, 387-416. doi:

$10.1080 / 15213269.2010 .525737$

Mather, G., Verstraten, F. A. J., \& Anstis, S. M. (1998). The motion aftereffect: A modern perspective: MIT Press.

McCreary, D. R., \& Sasse, D. K. (2000). An exploration of the drive for muscularity in adolescent boys and girls. Journal of American College Health, 48, 297-304.

Mercer Moss, F. J., Baddeley, R., \& Canagarajah, N. (2012). Eye Movements to Natural Images as a Function of Sex and Personality. 7(11), e47870. doi:10.1371/journal.pone.0047870

Mitchison, D., \& Mond, J. M. (2015). Epidemiology of eating disorders, eating-disordered behaviour, and body image disturbance in males: A narrative review. Journal of Eating Disorders, 3(1), 9. doi:10.1186/s40337-015-0058-y

Molbert, S. C., Klein, L., Thaler, A., Mohler, B. J., Brozzo, C., Martus, P., . . Giel, K. E. (2017). Depictive and metric body size estimation in anorexia nervosa and bulimia nervosa: A 
systematic review and meta-analysis. Clinical Psychology Review, 57, 21-31.

doi:10.1016/j.cpr.2017.08.005

Mond, J., Mitchison, D., Latner, J., Hay, P., Owen, C., \& Rodgers, B. (2013). Quality of life impairment associated with body dissatisfaction in a general population sample of women. BMC Public Health, 13, 920. doi:10.1186/1471-2458-13-920

Murray, S. B., Griffiths, S., \& Mond, J. M. (2016). Evolving eating disorder psychopathology: conceptualising muscularity-oriented disordered eating. Br J Psychiatry, 208(5), 414-415. doi:10.1192/bjp.bp.115.168427

Murray, S. B., Nagata, J. M., Brown, T. A., Calzo, J. P., Mitchison, D., Griffiths, S., . . Mond, J. M. (2017). The Enigma of Male Eating Disorders: A Critical Review and Synthesis. Clinical Psychology Review, 57, 1-11.

Olivardia, R., Pope Jr, H. G., Borowiecki III, J. J., \& Cohane, G. H. (2004). Biceps and body image: the relationship between muscularity and self-esteem, depression, and eating disorder symptoms. Psychology of Men \& Masculinity, 5(2), 112.

Palumbo, R., D’Ascenzo, S., \& Tommasi, L. (2015). Cross-category adaptation: exposure to faces produces gender aftereffects in body perception. Psychological Research, 79(3), 380-388.

Palumbo, R., Laeng, B., \& Tommasi, L. (2013). Gender-specific aftereffects following adaptation to silhouettes of human bodies. Visual Cognition, 21(1), 1-12. doi:10.1080/13506285.2012.753970

Pestilli, F., Viera, G., \& Carrasco, M. (2007). How do attention and adaptation affect contrast sensitivity? Journal of Vision, 7(7), 9-9. doi:10.1167/7.7.9

Pope Jr, H. G., Olivardia, R., Gruber, A., \& Borowiecki, J. (1999). Evolving ideals of male body image as seen through action toys. International Journal of Eating Disorders, 26(1), 65-72.

Pope Jr, H. G., Phillips, K. A., \& Olivardia, R. (2000). The Adonis Complex: The Secret Crisis of Male Body Obsession New York: Free Press (Simon \& Schuster). 
Rhodes, G., Jeffery, L., Evangelista, E., Ewing, L, Peters, M., \& Taylor, L. (2011). Enhanced attention amplifies face adaptation. Vision Research, 15, 1811-1819. doi: 10.1016/j.visres.2011.06.008

Sekunova, A., Black, M., Parkinson, L., \& Barton, J. J. (2013). Viewpoint and pose in body-form adaptation. Perception, 42(2), 176-186.

Slaby, R., \& Frey, K. (1975). Development of gender constancy and selective attention to samesex models. Child Development, 46, 849-856. doi: 10.2307/1128389

Specter, S., \& Wiss, D. (2014). Muscle dysmorphia: Where body image obsession, compulsive exercise, disordered eating, and substance abuse intersect in susceptible males. In: T. Brewerton \& A. Baker Dennis (Eds.) Eating disorders, addictions and substance use disorders. Springer: Berling, Heidelberg.

Stephen, I., Bickersteth, C., Mond, J., Stevenson, R., \& Brooks, K. (2016). No effect of featural attention on body size aftereffects. Frontier Psychology, 7: 1223. doi: 10.3389/fpsyg.2016.01223

Stephen, I. D., Hunter, K., Sturman, D., Mond, J., Stevenson, R. J., Brooks, K. R. (2019). Experimental manipulation of visual attention affects body size adaptation but not body dissatisfaction. International Journal of Eating Disorders, 52, 79-87.

\section{https://doi.org/10.1002/eat.22976}

Stephen, I. D., Sturman, D., Stevenson, R. J., Mond, J., \& Brooks, K. R. (2018). Visual attention mediates the relationship between body satisfaction and susceptibility to the body size adaptation effect. PLoS ONE, 13(1): e0189855.

\section{https://doi.org/10.1371/journal.pone.0189855}

Stice, E., \& Shaw, H. (2002). Role of body dissatisfaction in the onset and maintenance of eating pathology: A synthesis of research findings. Journal of Psychosomatic Research, 53, 985993. doi: 10.1016/S0022-3999(02)00488-9 
Striegel-Moore, R., Rosselli, F., Perrin, N., Debar, L., Wilson, G., May, A., \& Kraemer, H. (2009).

Gender difference in the prevalence of eating disorder symptoms. International Journal of Eating Disorders, 42, 471-474. doi: 10.1002/eat.20625

Sturman, D., Stephen, I., Mond, J., Stevenson, R., \& Brooks, K. (2017). Independent aftereffects of fat and muscle: Implications for neural encoding, body space representation, and body image disturbance. Scientific Reports, 7, 1-8. doi: 10.1038/srep40392

Taylor, M. J., \& Cooper, P. J. (1992). An experimental study of the effect of mood on body size perception. Behaviour research and therapy, 30(1), 53-58.

Thompson, P., \& Burr, D. (2009). Visual aftereffects. Current Biology, 19(1), R11-R14.

Tiddeman, B., Burt, M., \& Perrett, D. (2001). Prototyping and transforming facial textures for perception research. Computer Graphics and Applications, IEEE, 21, 42-50. doi:10.1109/38.946630

Tovée, M. J., Swami, V., Furnham, A., \& Mangalparsad, R. (2006). Changing perceptions of attractiveness as observers are exposed to a different culture. Evolution and Human Behavior, 27(6), 443-456.

Vartanian, L. R., Giant, C. L., \& Passino, R. M. (2001). “Ally McBeal vs. Arnold Schwarzenegger”: Comparing mass media, interpersonal feedback and gender as predictors of satisfaction with body thinness and muscularity. Social Behavior and Personality: an international journal, 29(7), 711-723.

Winkler, C., \& Rhodes, G. (2005). Percpetual adaptation affects attractiveness of female bodies. British Journal of Psychology, 96, 141-154. doi: 10.1348/000712605X36343

Wiseman, C.V., Gray, J.J., Mosimann, J.E., \& Ahrens, A.H. (1992). Cultural expectations of thinness in women: An update. International Journal of Eating Disorders, 11(1), 85-89. 
Table 1

Comparisons of Body Composition between Prototype Images

\begin{tabular}{lcc}
\hline Prototypes & Fat difference $(\mathrm{kg})$ & Muscle difference $(\mathrm{kg})$ \\
\hline High fat vs low fat male & $11.8^{*}$ & 2.6 \\
High muscle vs low muscle male & 1.2 & $8.9^{*}$ \\
High fat vs low fat female & $12.0^{* *}$ & -1.5 \\
High muscle vs low muscle female & 0.7 & $7.4^{*}$ \\
\hline
\end{tabular}

$* \mathrm{p}<.05 * * \mathrm{p}<.01$ 


\section{Figure Captions}

Figure 1. Examples of a female and a male body manipulated along the body fat and muscle mass dimensions, with the original image (centre) and 100\% manipulations towards the low fat, high fat, low muscle and high muscle prototypes.

Figure 2. Changes in perceived fat mass $\left(\triangle P S N_{f}\right)$ and muscle mass $\left(\triangle P S N_{m}\right)$ caused by adaptation, plotted in 2-D Cartesian body space, for all observers and stimuli. Error bars represent $95 \%$ Cls.

Figure 3. Changes in perceived fat mass $(\triangle \mathrm{PSN})$ and muscle mass $(\triangle \mathrm{PSN})$ caused by adaptation, plotted in 2-D Cartesian body space, for a) male and b) female observers. Error bars represent $95 \% \mathrm{Cls}$.

Figure 4. Changes in perceived fat mass $\left(\triangle P S N_{f}\right)$ and muscle mass $\left(\triangle P S N_{m}\right)$ caused by adaptation, plotted in 2-D Cartesian body space, for a) male and b) female body stimuli. Error bars represent $95 \%$ Cls.

Figure 5. Changes in perceived fat mass $\left(\triangle P S N_{f}\right)$ and muscle mass $\left(\triangle P S N_{m}\right)$ caused by adaptation, plotted in 2-D Cartesian body space, for a) own-gender and b) other-gender body stimuli. Error bars represent $95 \%$ Cls. 
Figure 1.

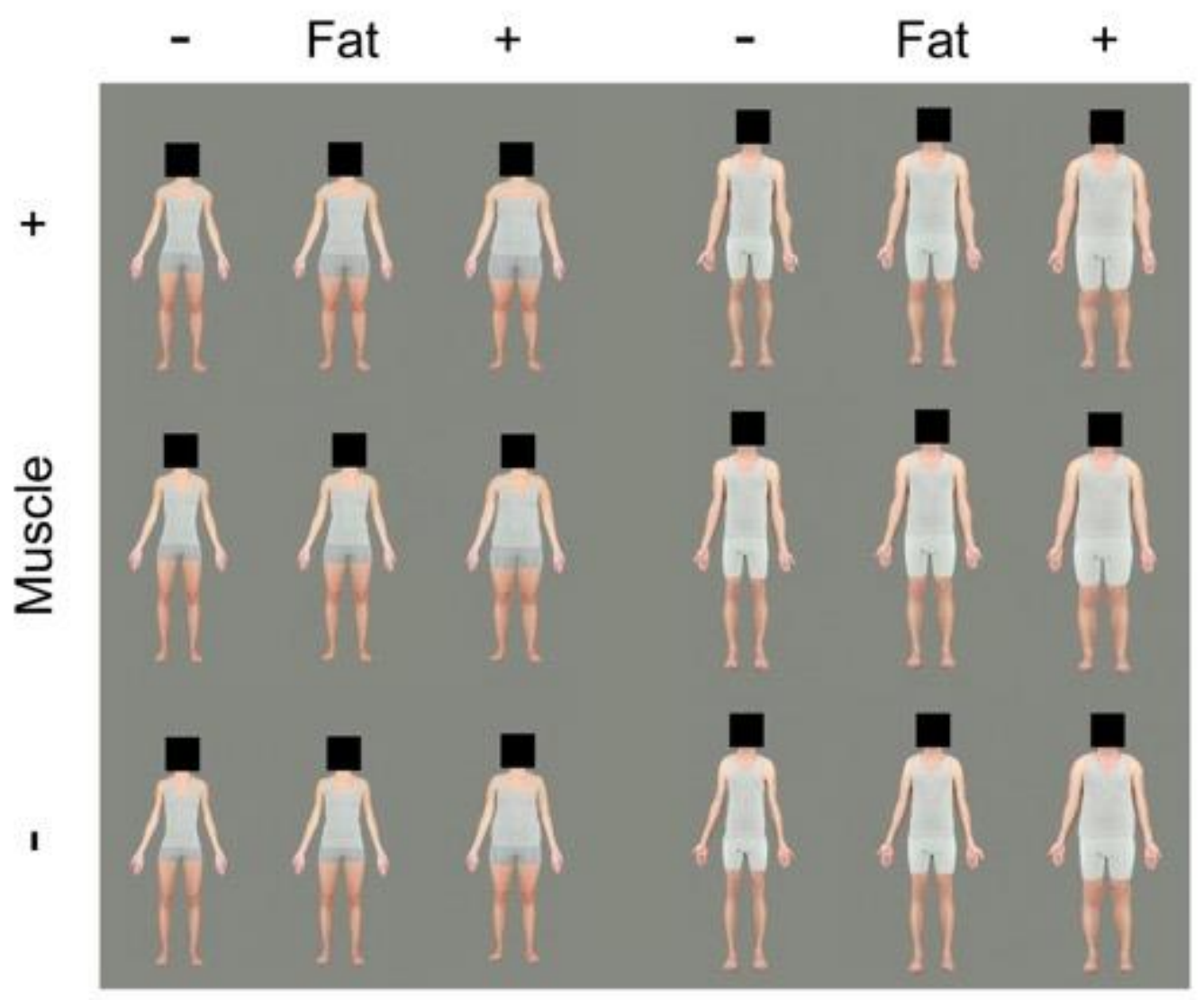

Female

Male 
Figure 2

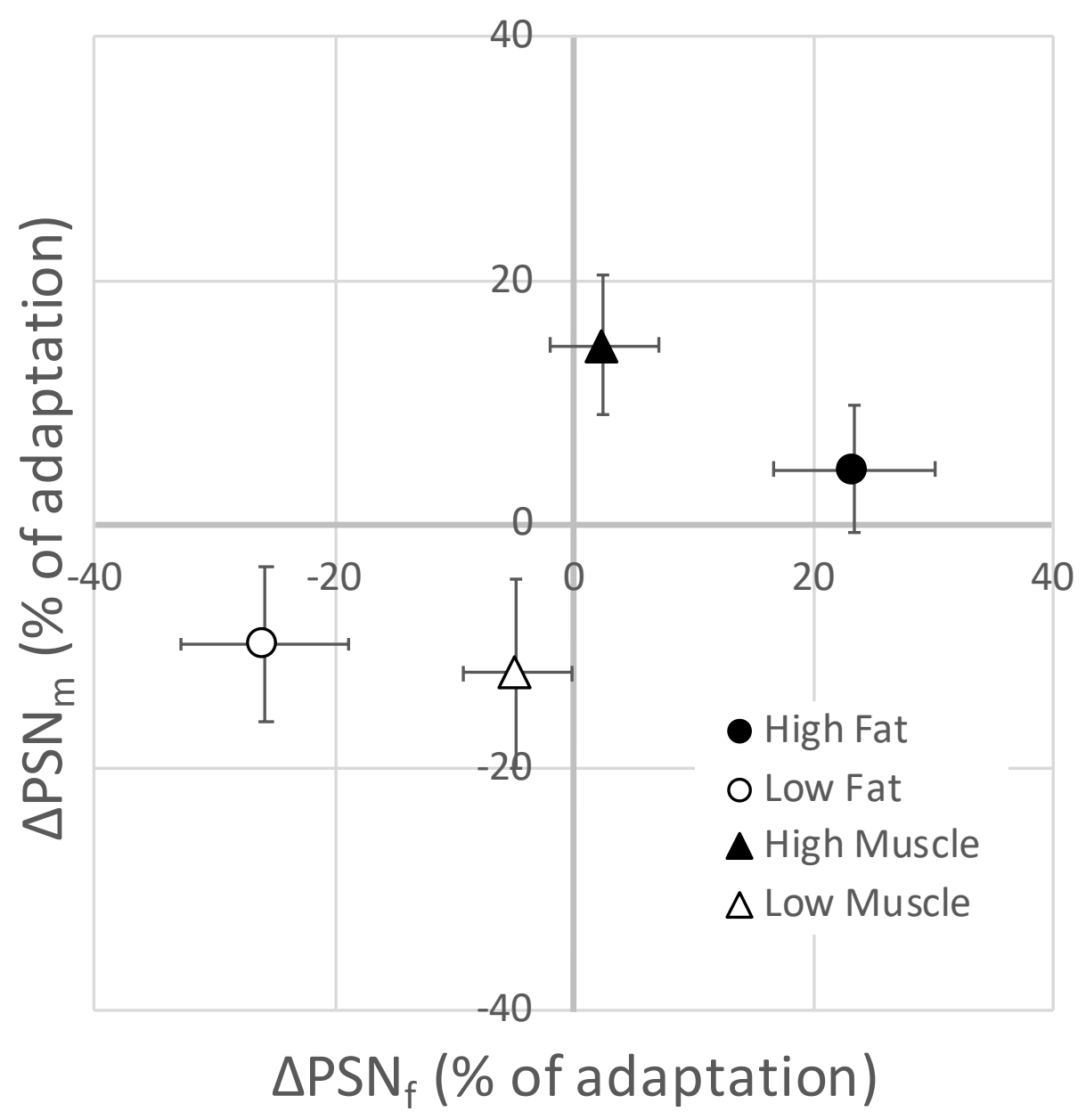


Figure 3

a) Male Observers

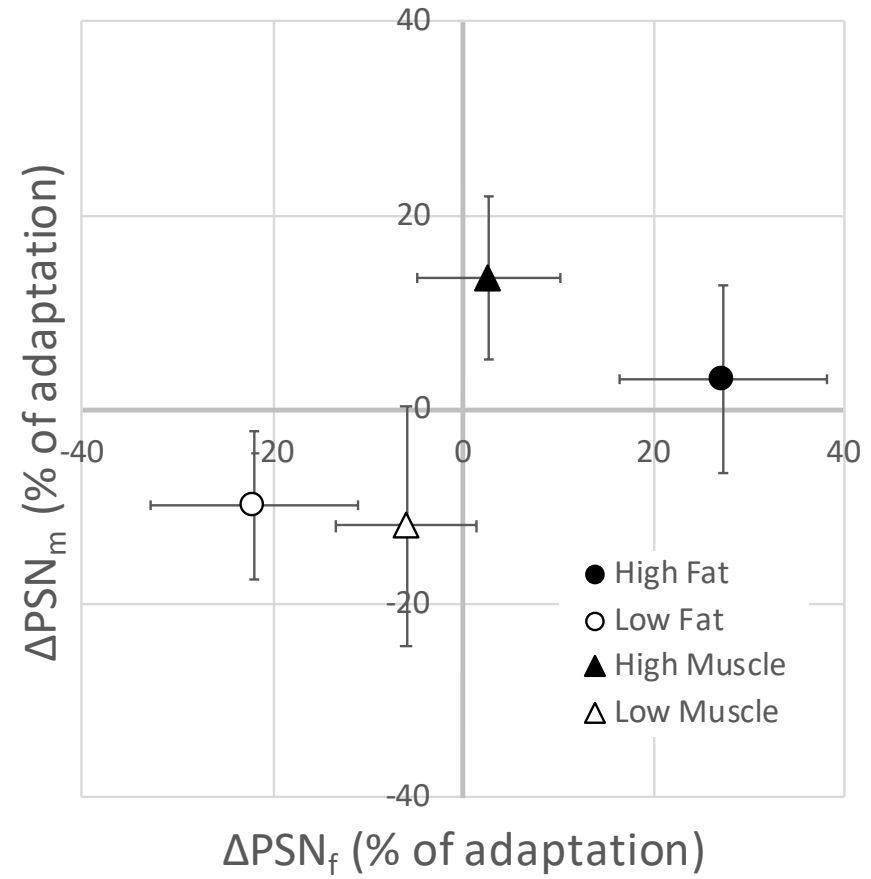

b) Female Observers

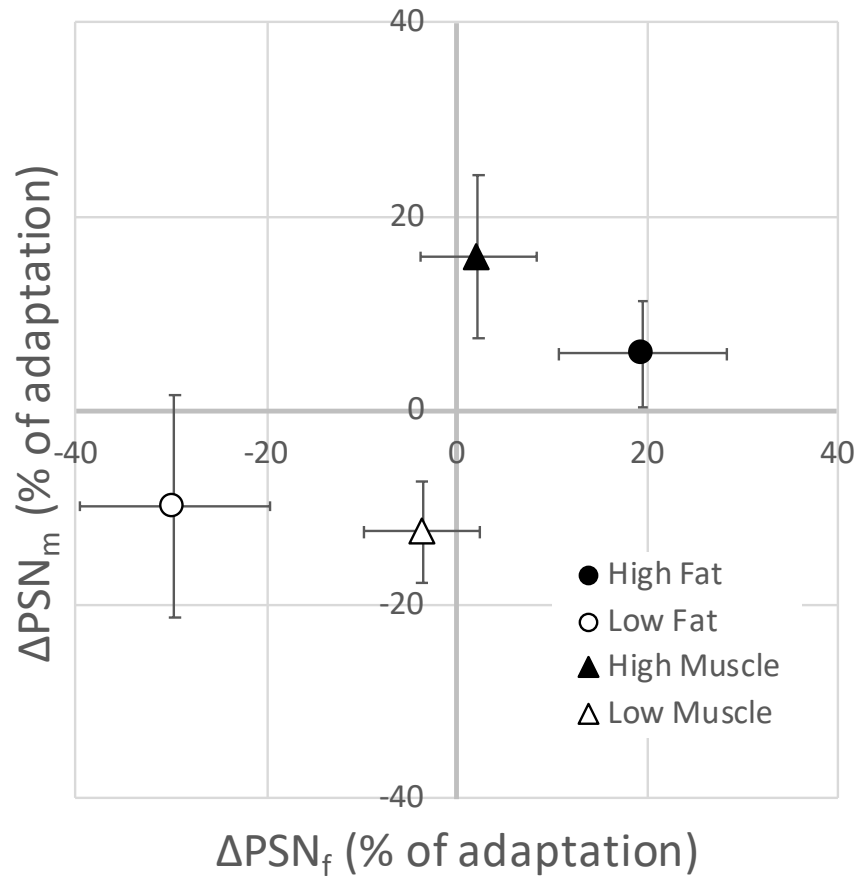


Figure 4

a) Male Stimuli

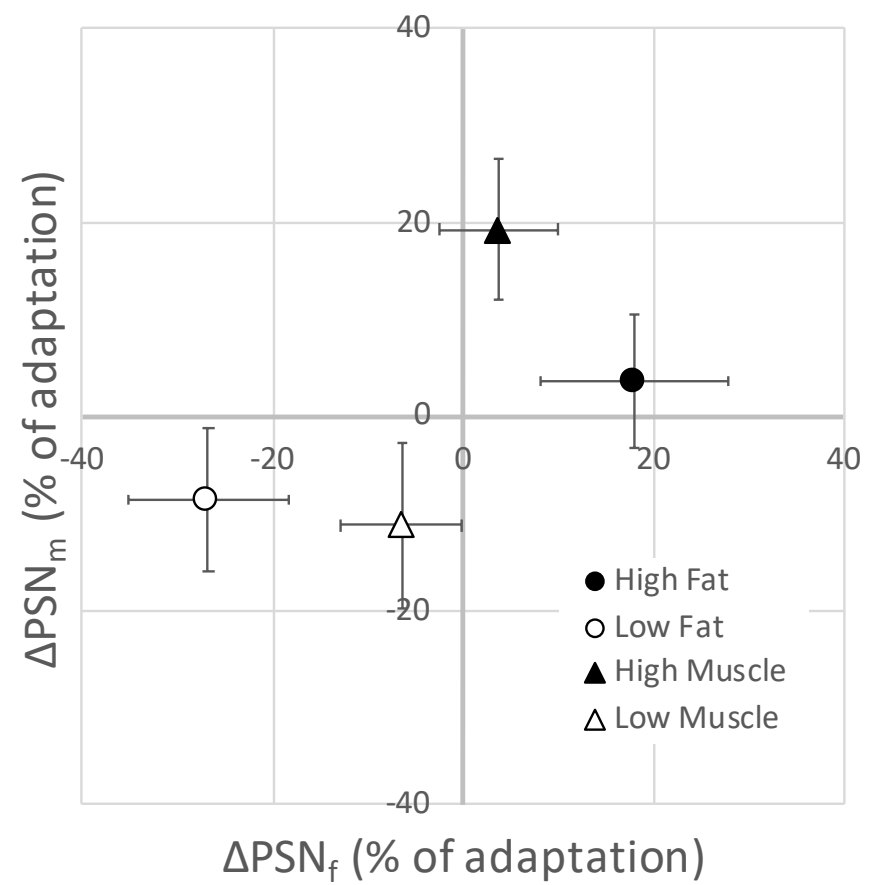

b) Female Stimuli

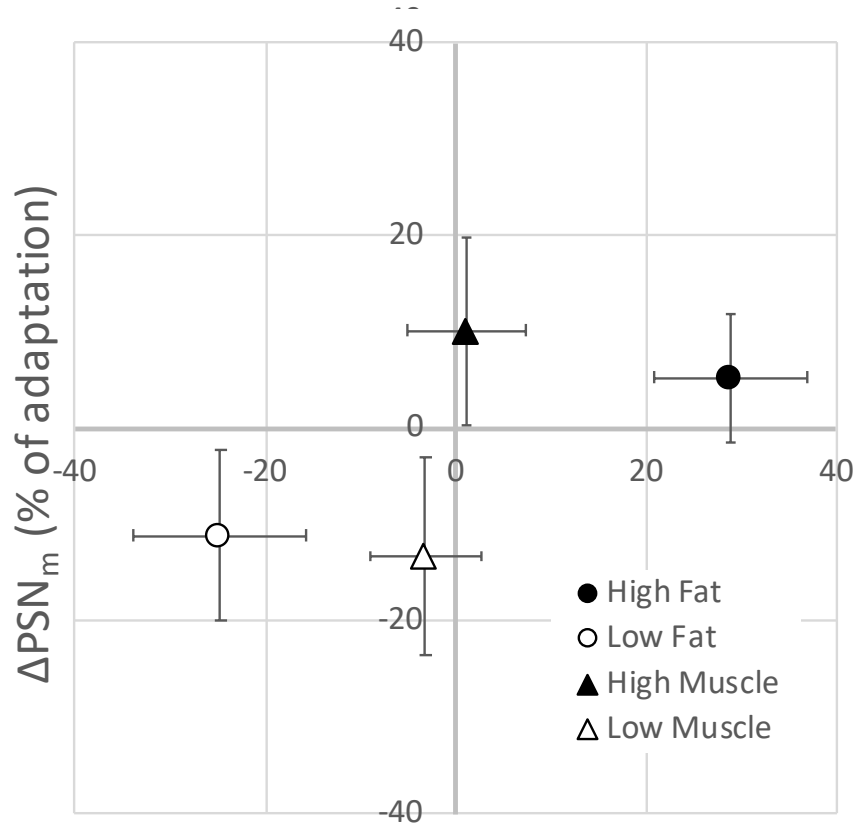

$\triangle \mathrm{PSN}_{\mathrm{f}}$ (\% of adaptation) 
Figure 5

a) Own Gender

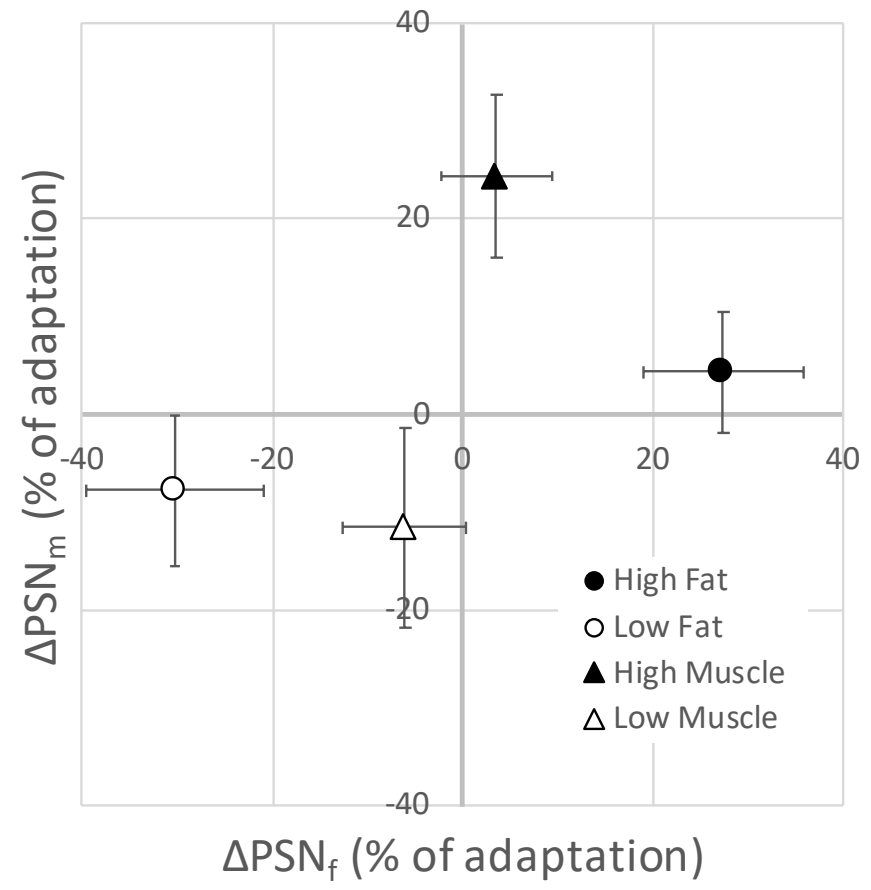

b) Other Gender

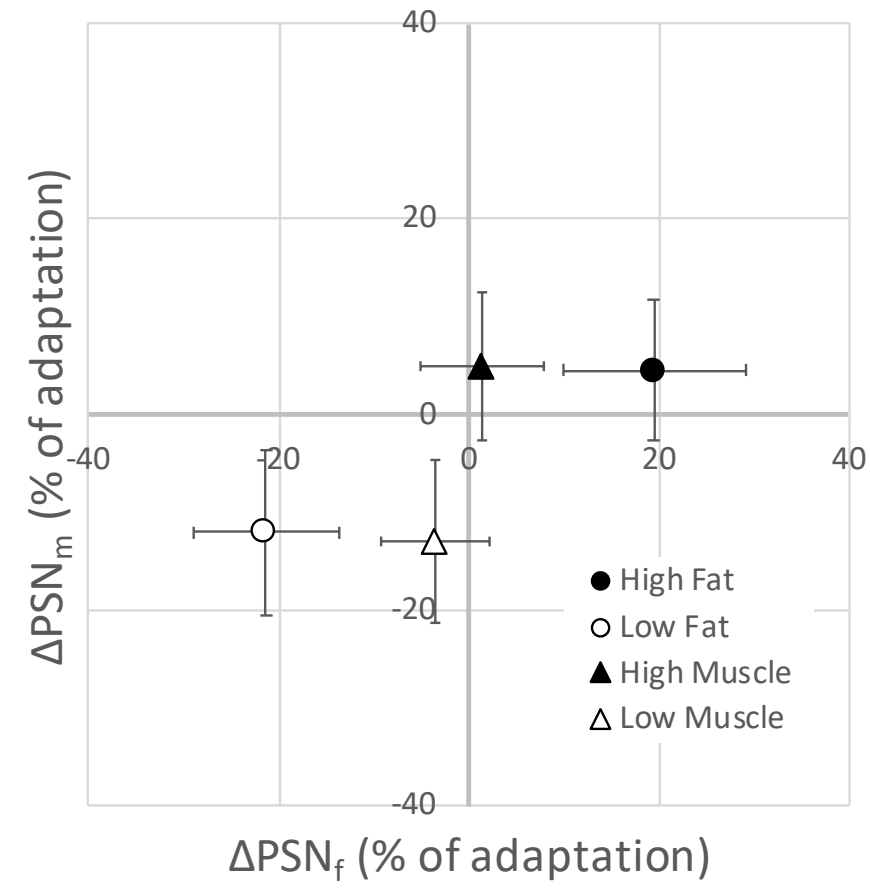


Appendix

Table 2:

Baseline PSN Means (SDs)

\begin{tabular}{|c|c|c|c|c|c|c|c|c|c|c|}
\hline $\begin{array}{l}\text { Adaptation } \\
\text { Dimension }\end{array}$ & $\begin{array}{c}\text { Adaptation } \\
\text { Direction }\end{array}$ & $\begin{array}{c}\text { Observer } \\
\text { Gender }\end{array}$ & $\begin{array}{c}\text { Female } \\
\text { Fat }\end{array}$ & $\begin{array}{l}\text { Female } \\
\text { Muscle }\end{array}$ & $\begin{array}{c}\text { Male } \\
\text { Fat }\end{array}$ & $\begin{array}{c}\text { Male } \\
\text { Muscle }\end{array}$ & $\begin{array}{c}\text { Same } \\
\text { Fat }\end{array}$ & $\begin{array}{c}\text { Same } \\
\text { Muscle }\end{array}$ & $\begin{array}{c}\text { Different } \\
\text { Fat }\end{array}$ & $\begin{array}{c}\text { Different } \\
\text { Muscle }\end{array}$ \\
\hline \multirow{4}{*}{ Fat } & \multirow[t]{2}{*}{ Low } & Male & $\begin{array}{c}5.38 \\
(1.86)\end{array}$ & $\begin{array}{c}6.88 \\
(1.61)\end{array}$ & $\begin{array}{c}7.09 \\
(1.42)\end{array}$ & $\begin{array}{c}6.11 \\
(1.53)\end{array}$ & \multirow{2}{*}{$\begin{array}{c}6.48 \\
(1.81)\end{array}$} & \multirow{2}{*}{$\begin{array}{c}6.12 \\
(2.10)\end{array}$} & \multirow{2}{*}{$\begin{array}{l}5.83 \\
(1.74)\end{array}$} & \multirow{2}{*}{$\begin{array}{c}6.77 \\
(1.48)\end{array}$} \\
\hline & & Female & $\begin{array}{c}5.86 \\
(1.99)\end{array}$ & $\begin{array}{c}6.13 \\
(2.44)\end{array}$ & $\begin{array}{c}6.28 \\
(1.55)\end{array}$ & $\begin{array}{c}6.65 \\
(1.37)\end{array}$ & & & & \\
\hline & \multirow[t]{2}{*}{ High } & Male & $\begin{array}{c}4.77 \\
(2.19)\end{array}$ & $\begin{array}{c}6.38 \\
(2.00)\end{array}$ & $\begin{array}{c}6.06 \\
(1.31)\end{array}$ & $\begin{array}{c}6.23 \\
(1.48)\end{array}$ & \multirow{2}{*}{$\begin{array}{c}6.06 \\
(1.90)\end{array}$} & \multirow{2}{*}{$\begin{array}{c}6.81 \\
(1.59)\end{array}$} & \multirow{2}{*}{$\begin{array}{l}5.74 \\
(2.29)\end{array}$} & \multirow{2}{*}{$\begin{array}{c}6.72 \\
(1.65)\end{array}$} \\
\hline & & Female & $\begin{array}{c}6.05 \\
(2.40) \\
\end{array}$ & $\begin{array}{c}7.39 \\
(1.53) \\
\end{array}$ & $\begin{array}{c}6.71 \\
(2.02) \\
\end{array}$ & $\begin{array}{c}7.05 \\
(1.16) \\
\end{array}$ & & & & \\
\hline \multirow{4}{*}{ Muscle } & \multirow[t]{2}{*}{ Low } & Male & $\begin{array}{c}5.06 \\
(2.23)\end{array}$ & $\begin{array}{c}5.54 \\
(2.46)\end{array}$ & $\begin{array}{c}5.87 \\
(0.94)\end{array}$ & $\begin{array}{c}6.11 \\
(1.43)\end{array}$ & \multirow{2}{*}{$\begin{array}{c}6.05 \\
(1.50)\end{array}$} & \multirow{2}{*}{$\begin{array}{c}6.74 \\
(1.83)\end{array}$} & \multirow{2}{*}{$\begin{array}{c}6.24 \\
(2.10)\end{array}$} & \multirow{2}{*}{$\begin{array}{c}6.54 \\
(2.20)\end{array}$} \\
\hline & & Female & $\begin{array}{c}6.24 \\
(1.91)\end{array}$ & $\begin{array}{l}7.38 \\
(2.00)\end{array}$ & $\begin{array}{c}7.42 \\
(1.07)\end{array}$ & $\begin{array}{c}7.53 \\
(1.36)\end{array}$ & & & & \\
\hline & \multirow[t]{2}{*}{ High } & Male & $\begin{array}{c}6.60 \\
(1.41)\end{array}$ & $\begin{array}{c}6.93 \\
(1.46)\end{array}$ & $\begin{array}{c}6.95 \\
(1.16)\end{array}$ & $\begin{array}{c}7.02 \\
(1.42)\end{array}$ & \multirow{2}{*}{$\begin{array}{c}6.48 \\
(1.57)\end{array}$} & \multirow{2}{*}{$\begin{array}{c}6.86 \\
(1.27)\end{array}$} & \multirow{2}{*}{$\begin{array}{c}6.70 \\
(1.16)\end{array}$} & \multirow{2}{*}{$\begin{array}{c}6.61 \\
(1.52)\end{array}$} \\
\hline & & Female & $\begin{array}{c}6.00 \\
(1.81)\end{array}$ & $\begin{array}{c}6.70 \\
(1.13)\end{array}$ & $\begin{array}{c}6.80 \\
(0.88)\end{array}$ & $\begin{array}{c}6.28 \\
(1.55)\end{array}$ & & & & \\
\hline
\end{tabular}

Table 2. Baseline PSN means and standard deviations (in brackets) for all groups and conditions.

Table 3:

Adaptation Level Means (SDs)

\begin{tabular}{|c|c|c|c|c|c|c|c|c|c|c|}
\hline $\begin{array}{l}\text { Adaptation } \\
\text { Dimension }\end{array}$ & $\begin{array}{c}\text { Adaptation } \\
\text { Direction }\end{array}$ & $\begin{array}{c}\text { Observer } \\
\text { Gender }\end{array}$ & $\begin{array}{c}\text { Female } \\
\text { Fat }\end{array}$ & $\begin{array}{l}\text { Female } \\
\text { Muscle }\end{array}$ & $\begin{array}{c}\text { Male } \\
\text { Fat }\end{array}$ & $\begin{array}{c}\text { Male } \\
\text { Muscle }\end{array}$ & $\begin{array}{c}\text { Same } \\
\text { Fat }\end{array}$ & $\begin{array}{c}\text { Same } \\
\text { Muscle }\end{array}$ & $\begin{array}{c}\text { Different } \\
\text { Fat }\end{array}$ & $\begin{array}{c}\text { Different } \\
\text { Muscle }\end{array}$ \\
\hline \multirow{4}{*}{ Fat } & \multirow[t]{2}{*}{ Low } & Male & $\begin{array}{c}0.38 \\
(0.62)\end{array}$ & & $\begin{array}{c}1.31 \\
(1.40)\end{array}$ & & \multirow{2}{*}{$\begin{array}{c}1.03 \\
(1.20)\end{array}$} & \multirow{2}{*}{\multicolumn{2}{|c|}{$\begin{array}{c}0.59 \\
(0.80)\end{array}$}} & \\
\hline & & Female & $\begin{array}{c}0.75 \\
(0.93)\end{array}$ & & $\begin{array}{c}0.81 \\
(0.91)\end{array}$ & & & & & \\
\hline & \multirow[t]{2}{*}{ High } & Male & $\begin{array}{c}10.38 \\
(1.59)\end{array}$ & & $\begin{array}{l}11.44 \\
(0.81)\end{array}$ & & \multirow{2}{*}{$\begin{array}{l}11.25 \\
(1.27)\end{array}$} & \multirow{2}{*}{\multicolumn{2}{|c|}{$\begin{array}{l}10.94 \\
(1.50)\end{array}$}} & \\
\hline & & Female & $\begin{array}{l}11.06 \\
(1.61)\end{array}$ & & $\begin{array}{l}11.50 \\
(1.21)\end{array}$ & & & & & \\
\hline \multirow{4}{*}{ Muscle } & \multirow[t]{2}{*}{ Low } & Male & & $\begin{array}{c}0.75 \\
(1.57)\end{array}$ & & $\begin{array}{c}0.63 \\
(1.02)\end{array}$ & & \multirow{2}{*}{$\begin{array}{l}1.06 \\
(1.41)\end{array}$} & & \multirow{2}{*}{$\begin{array}{l}1.16 \\
(1.44)\end{array}$} \\
\hline & & Female & & $\begin{array}{c}1.50 \\
(1.63)\end{array}$ & & $\begin{array}{c}1.56 \\
(1.21)\end{array}$ & & & & \\
\hline & \multirow[t]{2}{*}{ High } & Male & & $\begin{array}{l}11.69 \\
(0.79)\end{array}$ & & $\begin{array}{l}11.81 \\
(0.40)\end{array}$ & & \multirow{2}{*}{$\begin{array}{l}11.78 \\
(0.49)\end{array}$} & & \multirow{2}{*}{$\begin{array}{l}11.63 \\
(0.79)\end{array}$} \\
\hline & & Female & & $\begin{array}{l}11.75 \\
(0.58)\end{array}$ & & $\begin{array}{l}11.56 \\
(0.81)\end{array}$ & & & & \\
\hline
\end{tabular}

Table 3: Adaptor level means and standard deviations (in brackets) used in all conditions. While 0 represents the lowest value stimulus in the set, 12 represents the highest. 
Table 4:

Adaptor Extremity Means (SDs)

\begin{tabular}{|c|c|c|c|c|c|c|c|c|c|c|}
\hline $\begin{array}{l}\text { Adaptation } \\
\text { Dimension }\end{array}$ & $\begin{array}{c}\text { Adaptation } \\
\text { Direction }\end{array}$ & $\begin{array}{c}\text { Observer } \\
\text { Gender }\end{array}$ & $\begin{array}{c}\text { Female } \\
\text { Fat }\end{array}$ & $\begin{array}{l}\text { Female } \\
\text { Muscle }\end{array}$ & $\begin{array}{c}\text { Male } \\
\text { Fat }\end{array}$ & $\begin{array}{c}\text { Male } \\
\text { Muscle }\end{array}$ & $\begin{array}{c}\text { Same } \\
\text { Fat }\end{array}$ & $\begin{array}{c}\text { Same } \\
\text { Muscle }\end{array}$ & $\begin{array}{c}\text { Different } \\
\text { Fat }\end{array}$ & $\begin{array}{c}\text { Different } \\
\text { Muscle }\end{array}$ \\
\hline \multirow{4}{*}{ Fat } & \multirow[t]{2}{*}{ Low } & Male & $\begin{array}{l}-5.00 \\
(1.51)\end{array}$ & & $\begin{array}{l}-5.78 \\
(0.28)\end{array}$ & & \multirow{2}{*}{$\begin{array}{l}-5.44 \\
(1.02)\end{array}$} & \multirow{2}{*}{\multicolumn{2}{|c|}{$\begin{array}{l}-5.23 \\
(1.24)\end{array}$}} & \\
\hline & & Female & $\begin{array}{l}-5.11 \\
(1.35)\end{array}$ & & $\begin{array}{l}-5.47 \\
(0.89)\end{array}$ & & & & & \\
\hline & \multirow[t]{2}{*}{ High } & Male & $\begin{array}{c}5.61 \\
(0.93)\end{array}$ & & $\begin{array}{c}5.38 \\
(0.70)\end{array}$ & & \multirow{2}{*}{$\begin{array}{l}5.19 \\
(0.86)\end{array}$} & \multirow{2}{*}{\multicolumn{2}{|c|}{$\begin{array}{l}5.20 \\
(1.15)\end{array}$}} & \\
\hline & & Female & $\begin{array}{c}5.01 \\
(0.99)\end{array}$ & & $\begin{array}{c}4.79 \\
(1.22)\end{array}$ & & & & & \\
\hline \multirow{4}{*}{ Muscle } & \multirow[t]{2}{*}{ Low } & Male & & $\begin{array}{l}-4.79 \\
(1.38)\end{array}$ & & $\begin{array}{l}-5.48 \\
(0.72)\end{array}$ & & \multirow{2}{*}{$\begin{array}{l}-5.68 \\
(0.71)\end{array}$} & & \multirow{2}{*}{$\begin{array}{l}-5.38 \\
(1.17)\end{array}$} \\
\hline & & Female & & $\begin{array}{l}-5.88 \\
(0.67)\end{array}$ & & $\begin{array}{l}-5.97 \\
(0.43)\end{array}$ & & & & \\
\hline & \multirow[t]{2}{*}{ High } & Male & & $\begin{array}{c}4.76 \\
(0.83)\end{array}$ & & $\begin{array}{c}4.80 \\
(1.18)\end{array}$ & & \multirow{2}{*}{$\begin{array}{c}4.92 \\
(0.98)\end{array}$} & & \multirow{2}{*}{$\begin{array}{c}5.02 \\
(0.93)\end{array}$} \\
\hline & & Female & & $\begin{array}{c}5.05 \\
(0.76)\end{array}$ & & $\begin{array}{c}5.28 \\
(0.98)\end{array}$ & & & & \\
\hline
\end{tabular}

Table 4: Adaptor extremity means and standard deviations (in brackets) used in all conditions. Adaptor extremity represents the difference between the adaptor level and the baseline in stimulus steps, and was calculated independently for each observer. 